\title{
Die hypothetische Einwilligung im Strafrecht
}

Überlegungen zu den dogmatischen Grundlagen und zum Anwendungsbereich der Rechtsfigur

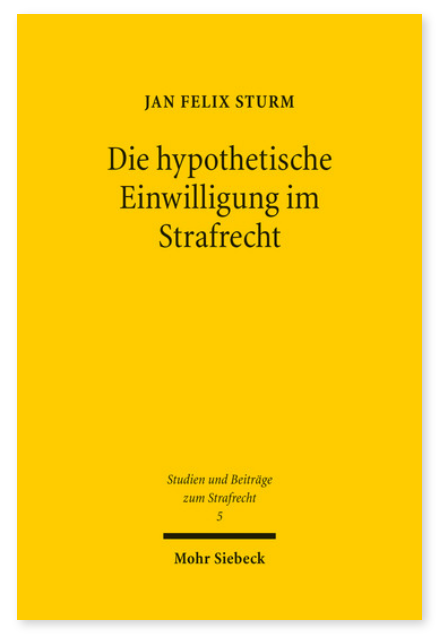

2016. XVII, 297 Seiten. StudStR 5

ISBN 978-3-16-154712-6

DOI 10.1628/978-3-16-154712-6

eBook PDF $89,00 €$

ISBN 978-3-16-154705-8

fadengeheftete Broschur $89,00 €$
Die hypothetische Einwilligung ist als strafbarkeitseinschränkende Figur in der Rechtsprechung zum Arztstrafrecht fest etabliert, in der Literatur jedoch hoch umstritten. Lässt sie sich als Ausdruck einer allgemeinen dogmatischen Struktur verstehen, nämlich als Baustein einer Lehre von der objektiven Zurechnung auf Rechtswidrigkeitsebene? Zur Beantwortung dieser Kernfrage setzt Jan Felix Sturm bei den Grundlagen der Zurechnungslehre an und führt den Streit um die Anerkennung der hypothetischen Einwilligung auf unterschiedliche Autonomieverständnisse zurück. Breiteren Raum als in der bisherigen Diskussion nehmen dabei Überlegungen zur Übertragbarkeit der hypothetischen Einwilligung auf Gebiete außerhalb des Arztstrafrechts ein. Im Ergebnis bewertet der Autor die hypothetische Einwilligung in den untersuchten Feldern kritisch - nicht aber, weil ihre Integration in das Strafrechtssystem konstruktiv ausgeschlossen wäre, sondern wegen des favorisierten Autonomieverständnisses.

Jan Felix Sturm Geboren 1984; Studium der Rechtswissenschaft an der Bucerius Law School in Hamburg und der Willamette University in Salem (Oregon, USA); wissenschaftlicher Mitarbeiter an der Bucerius Law School und der Humboldt-Universität zu Berlin; Referendariat am Kammergericht in Berlin mit Stationen in Brüssel und Karlsruhe; seit 2016 Rechtsanwalt in Hamburg.
Jetzt bestellen:

https://mohrsiebeck.com/buch/die-hypothetische-einwilligung-im-strafrecht-9783161547126?no_cache=1

order@mohrsiebeck.com

Telefon: +49 (0)7071-923-17

Telefax: +49(0)7071-51104 